\title{
Impact of Physical Properties of Workpiece Material on Material Removal Rate at EDM
}

\author{
L'. STRAKA ${ }^{1}, \mathrm{G}$. DITTRICH ${ }^{2}$ \\ ${ }^{1}$ Technical University of Kosice, Faculty of Manufacturing Technologies with a seat in Presov, Department of \\ Automobile and Manufacturing Technologies, luboslav.straka@tuke.sk \\ ${ }^{2}$ Technical University of Kosice, Faculty of Manufacturing Technologies with a seat in Presov, Department of \\ Automobile and Manufacturing Technologies, gabriel.dittrich@tuke.sk
}

Abstract. The volume stock removal from the workpiece during the EDM is one of the important parameters that characterize the productivity of the electro-erosion process itself. Therefore, in terms of the economic efficiency of the electro-erosion process, it is appropriate that the value of the MRR parameter is as high as possible. The paper describes the results of experimental research to identify the extent of influence of the physical properties of the workpiece material on the workpiece material removal rate at EDM. The experiments were carried out using an Aggregron Hyperspark 3 electro-erosion machine on selected tool steels. As a tool electrode material for experimental purposes, graphite with the designation EX-60 was chosen because of its practical advantages.

\section{Introduction}

With continued development of the engineering industry, progressive machining technologies are becoming increasingly prominent. These include the Electrical Discharge Machining [1]. At present, they are an indispensable part of production systems not only in Slovakia but also in other advanced countries of the world. This progressive technology is mainly used in companies dedicated to the production of various tools for the consumer and automotive industries [2]. Without this progressive machining technology, it would be very difficult to manufacture complex moulds for die-casting metals, moulds for injection moulding, stamping and shearing tools from hard-to-machinable materials. It is used in addition to the machining of hard-to-machinable materials is also found in the machining of complex shaped parts of the workpiece [3]. Among the hard-to-machinable materials also include tool steel. With their specific properties, they have, for many times, an almost insurmountable obstacle for classical machining technologies [4]. For electrical discharge machining the hardness of the workpiece material [5] is not a decisive criterion. However, an important parameter is its electrical and thermal conductivity. These properties of the workpiece material primarily specify its chemical composition. From it to some extent it depends not only on the final quality of the machined surface, but also the intensity of the workpiece material removal. In the case of very low workpiece material removal, there is a significant loss of productivity in the electro-erosion process [6]. This consequently makes this machining process less economical. 


\section{Material and methods of work}

In the experiments, Agietron Hyperspark 3 electro-erosive equipment (Fig. 1) from the Swiss company GF Agie Charmille was used to make the samples. It is a three-dimensional vertical CNC electro-erosion device which is used in practice for digging. Its application is mainly in the production of complex molds for casting metals under pressure and complex instruments for the forming of difficult to machine materials.

\begin{tabular}{|l|l|}
\hline Basic device parameters & \multicolumn{1}{|c|}{ Maximum range } \\
\hline Max. Axis Travel X/Y/Z & $880 \times 680 \times 350 \mathrm{~mm}$ \\
\hline Max. Work Table Size & $800 \times 600 \mathrm{~mm}$ \\
\hline Max. Workpiece Weight & $800 \mathrm{~kg}$ \\
\hline Max. Electrode Weight & $100 \mathrm{~kg}$ \\
\hline Max. Machining current & $72 \mathrm{~A}$ \\
\hline Total machine weight & $3900 \mathrm{~kg}$ \\
\hline Dielectric fluid (capacity) & oil (400 $\mathrm{l})$ \\
\hline
\end{tabular}

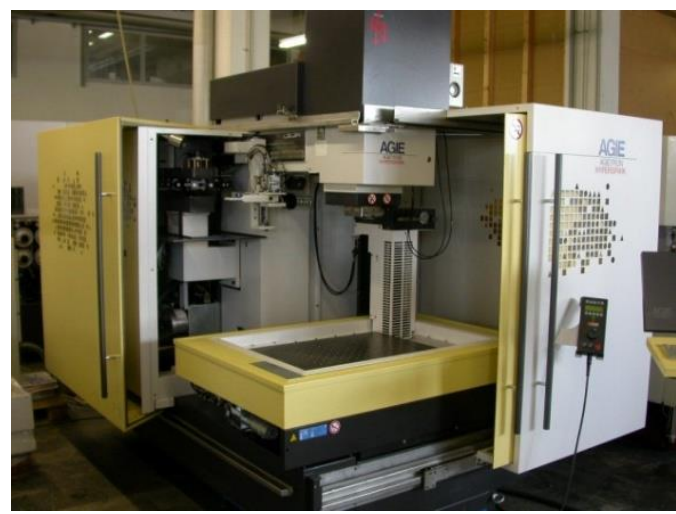

Figure 1. The electroerosion equipment AGIETRON HYPERSPARK 3 used for the production of experimental samples.

The SPEKTRO TEST CCD spectrometer was used to determine the exact chemical composition of the experimental samples (Fig. 2). It is a equipment that is used in practice to verify or identify a material based on a chemical composition analysis. Using the device was made a detailed spectral analysis of samples of materials used. The analysis was carried out in a protective atmosphere of argon.

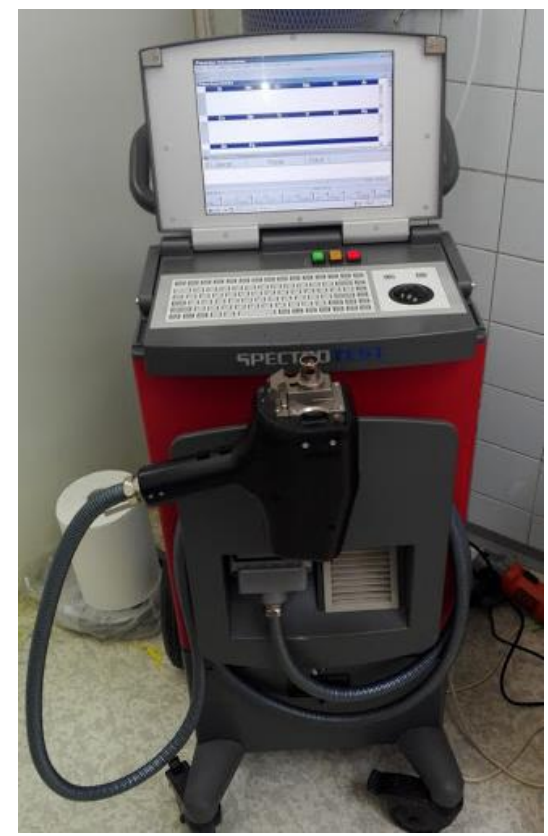

\begin{tabular}{|l|l|}
\hline Basic device parameters & \multicolumn{1}{|c|}{ Maximum range } \\
\hline Dimension W/L/H & $670 \times 425 \times 330 \mathrm{~mm}$ \\
\hline Max. Weight & $3.3 \mathrm{~kg}$ \\
\hline Analyzer & Arc $/$ spark \\
\hline Range of wavelengths & $174-670 \mathrm{~nm}$ \\
\hline Battery Life & 800 measurements \\
\hline
\end{tabular}

Figure 2. Spectrometer SPEKTRO TEST CCD.

In the production of samples, graphite with the designation EX-60 was used as tool electrode material. This type of material has been chosen because it has many advantages over $\mathrm{Cu}$ tool electrodes. This is 
in particular the higher productivity of the electroerosion process and thus the favourable economic efficiency in machining with this progressive technology.

Advantages of using graphite versus $\mathrm{Cu}$ in the manufacture of tool electrodes:

$\checkmark$ graphite has a lower thermal expansion compared to $\mathrm{Cu} 4$ times, which guarantees higher machining accuracy [7];

$\checkmark$ graphite also allows the production of thin-walled electrode tools;

$\checkmark$ when using thin-walled graphite electrodes there is no deformation because there is no internal tension in the graphite;

$\checkmark$ graphite has a 5-fold lower density compared with $\mathrm{Cu}$, resulting in a 5-fold lower the weight of the tool electrode while maintaining the same dimensions;

$\checkmark$ graphite compared to $\mathrm{Cu}$ allows machining 4 times the higher cutting speed, which shortens the production time of the graphite tool electrode,

$\checkmark$ graphite electrodes compared to $\mathrm{Cu}$ show much less wear during electroerosal machining [8];

$\checkmark$ graphite electrodes, compared to $\mathrm{Cu}$, make it possible to produce sharper edges.

In the experiments, the tool shaped electrodes of circular cross-section (Fig. 3) with diameter $\phi 10 \mathrm{~mm}$ and length of $100 \mathrm{~mm}$ were used.

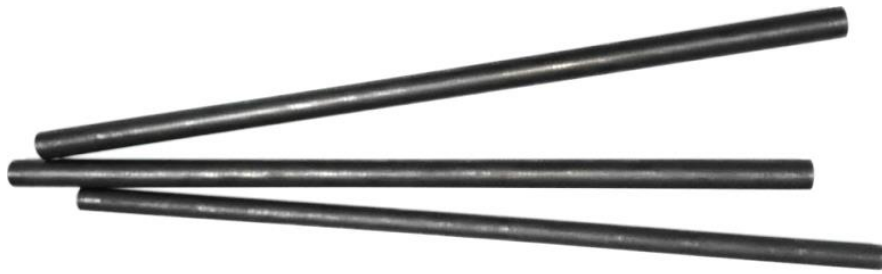

Figure 3. Semi-products graphite EX-60 used for the manufacturing of tool electrodes.

It is a material that has versatile application in electrical discharge machining. It can be used for both roughing and precision finishing operations. In the following tab. 1 are the basic properties of EX-60 graphite used in the experiment.

\begin{tabular}{|c|c|c|c|c|c|}
\hline Mark & $\begin{array}{c}\text { Density } \\
\left(\mathrm{g} . \mathrm{cm}^{-3}\right)\end{array}$ & $\begin{array}{c}\text { Hardness } \\
\text { (Shore) }\end{array}$ & $\begin{array}{c}\text { Specific } \\
\text { electrical resistance } \\
\left(\mu \Omega . \mathrm{cm}^{-1}\right)\end{array}$ & $\begin{array}{c}\text { Flexural strength } \\
(\mathrm{MPa})\end{array}$ & $\begin{array}{c}\text { Average grain } \\
\text { size } \\
(\mu \mathrm{m})\end{array}$ \\
\hline EX-60 & 1,8 & 62 & 1300 & 80 & 10 \\
\hline
\end{tabular}

Table 1. The basic properties of graphite EX-60 used in the experiment.

Experimental samples were made of tool steels. From each group of tool steels, i.e., unalloyed, alloyed and high-speed steels, one material was chosen. It was specifically the tool carbon steel EN C45W (Fig. 4), tool alloy steel EN X36 CrMoV5 and tool high speed steel EN HS6-5-2. 


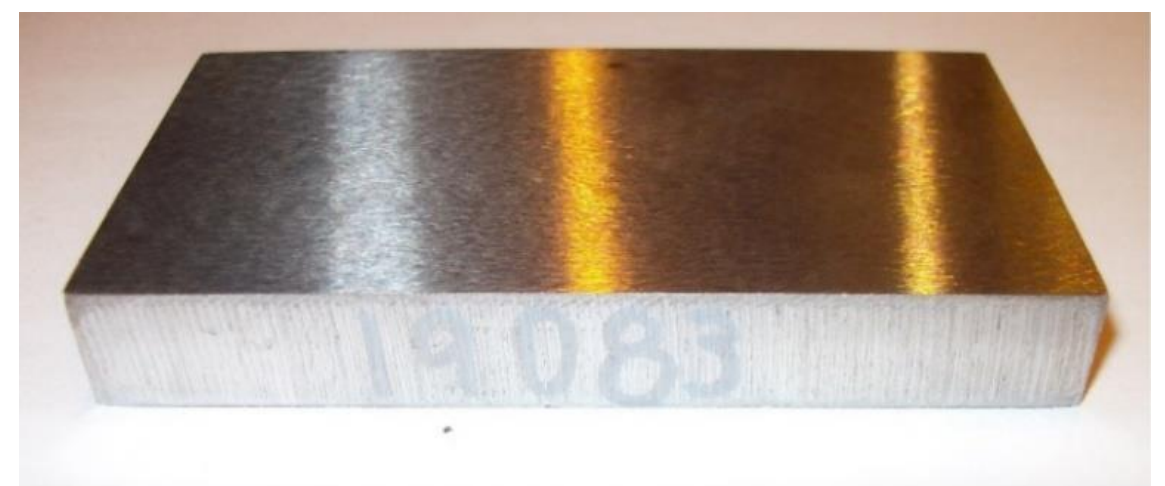

Figure 4. Experimental sample of carbon tool steel EN C45W (W. No. 1.1730) used in the experiment.

Tool carbon steel EN C45W (W.Nr. 1.1730) is mainly supplied in an annealed condition. The required hardness of the base material of about $58 \mathrm{HRC}$ is achieved by hardening. It is characterized by high toughness, strength, impact resistance with sufficient surface hardness (hard surface - tough core). It is used for the production of moulds for pressure casting of metals, moulds for injection moulding and various implements and tools. The experiment was also used alloyed tool steel with the designation EN CrMoV5 X 36 (W. Nr 1.2340). It is a chromium-molybdenum-vanadium alloy steel intended for tools for hot work. It has a high degree of resistance to heat shock and fatigue, has a relatively high strength at elevated temperatures, high toughness and tear strength, good through-hardening and dimensional stability during hardening. It is mainly used for the production of tools for hot work, for the production of moulds for moulding and for pressure casting and the like. Another material used in the experiment was the high-speed steel marked EN HS6-5-2 (W. No. 1.3343). It is a powerful highspeed steel with increased toughness and lighter machinability when grinding, but is more prone to decarburization than other high-speed steel. It is used for tools for cold work and for the most stressed tools for machining materials with medium and higher strength. Based on experimental measurements using spectrometer equipment SPEKTRO TEST CCD it was found the chemical composition of said tool steels. The identified percentages of their chemical elements are shown in the following tab. 2 .

\begin{tabular}{|c|c|c|c|c|c|c|c|c|c|}
\hline \multicolumn{10}{|c|}{ Chemical composition of steel } \\
\hline \multirow{2}{*}{ Steel } & \multicolumn{9}{|c|}{ Percentage of elements (\%) } \\
\hline & $\mathrm{C}$ & $\mathrm{Si}$ & $\mathrm{Mn}$ & $\mathrm{Cr}$ & Mo & $\mathrm{V}$ & $\mathrm{W}$ & $\mathrm{P}$ & $\mathrm{S}$ \\
\hline EN C45W & 0.40 & 0.35 & 0.78 & & & & & $\max .0 .030$ & $\max .0 .030$ \\
\hline EN X36 CrMoV5 & 0.41 & 0.26 & 0.49 & 4.28 & 1.28 & 0.37 & & $\max .0 .035$ & $\max .0 .035$ \\
\hline EN HS6-5-2 & 0.82 & 0.27 & 0.38 & 4.50 & 4.83 & 2.02 & 6.24 & $\max .0 .030$ & $\max .0 .030$ \\
\hline
\end{tabular}

Table 2. Measured values of chemical composition of tool steels ENC45W, EN X36CrMoV5 and EN HS6-5-2.

As mentioned earlier, the MRR when EDM with the graphite tool electrode EX-60 substantially influences the electrical conductivity of the machined material [9]. However, this is largely dependent on the percentage composition of its chemical elements. The following tab. 3 shows the selected physical properties of tool steels used in the experiment. 
DOI: 10.21791/IJEMS.2019.1.29.

\begin{tabular}{|l|c|c|c|c|c|}
\hline \multicolumn{1}{|c|}{ Steel } & $\begin{array}{c}\text { Electrical } \\
\text { conductivity } \\
{\left[\text { S.m.mm- } \mathrm{mm}^{-2}\right]}\end{array}$ & $\begin{array}{c}\text { Electric } \\
\text { resistivity } \\
{\left[\Omega \cdot \mathrm{mm}^{2} \cdot \mathrm{m}^{-1}\right]}\end{array}$ & $\begin{array}{c}\text { Thermal } \\
\text { Conductivity } \\
{\left[\mathrm{W} \cdot \mathrm{m}^{-1} \cdot \mathrm{K}^{-1}\right]}\end{array}$ & $\begin{array}{c}\text { Melting } \\
\text { point } \\
{\left[{ }^{\circ} \mathrm{C}\right]}\end{array}$ & $\begin{array}{c}\text { Density } \\
\left(\mathrm{kg}^{-1} \mathrm{dm}^{-3}\right)\end{array}$ \\
\hline EN C45W & 8.33 & 0.12 & 50 & 1460 & 7.85 \\
\hline EN X36 CrMoV5 & 7.25 & 0.35 & 45 & 1455 & 7.80 \\
\hline EN HS6-5-2 & 6.54 & 0.54 & 42 & 1432 & 8.14 \\
\hline
\end{tabular}

Table 3. Selected physical properties of tool steels used in the experiment.

\section{Results of experimental measurements}

Material Removal Rate (MRR) is considered to be an important output parameter in electrical discharge machining. This parameter comprehensively characterizes the amount of material removed from the workpiece during EDM. MRR is generally defined by the amount of material removal $\left(\mu \mathrm{m}^{3}\right.$, $\mathrm{mm}^{3}$ ) per unit time (min, s).

Mathematically, it can be expressed by formula (1):

$$
M R R=\frac{V_{m}}{t}\left[\mathrm{~mm}^{3} \cdot \mathrm{min}^{-1}\right]
$$

where: $V_{m}$ - the volume amount of material removed from a workpiece $\left[\mathrm{mm}^{3}\right]$,

$t$ - machining time [min].

As mentioned above, MRR is significantly influenced by the physical properties of the workpiece $[10,11]$, in particular the electrical conductivity $G$ and the thermal conductivity $\lambda[12]$. On the basis of a preliminary analysis of the impact of these factors on MRR in EDM of tool steels [13] with graphite tool electrode EX-60 experiments were carried out. From the results of these measurements, the graphical dependencies were subsequently constructed, which describe the influence of the selected factors on the MRR.

The graphs in Fig. 5 and 6 detail the dependence of MRR on the electrical conductivity $G$ and the thermal conductivity $\lambda$ of the workpiece in the EDM of tool steels EN C45W, EN X36CrMoV5 and EN HS6-5-2 with the graphite tool electrode EX-60.

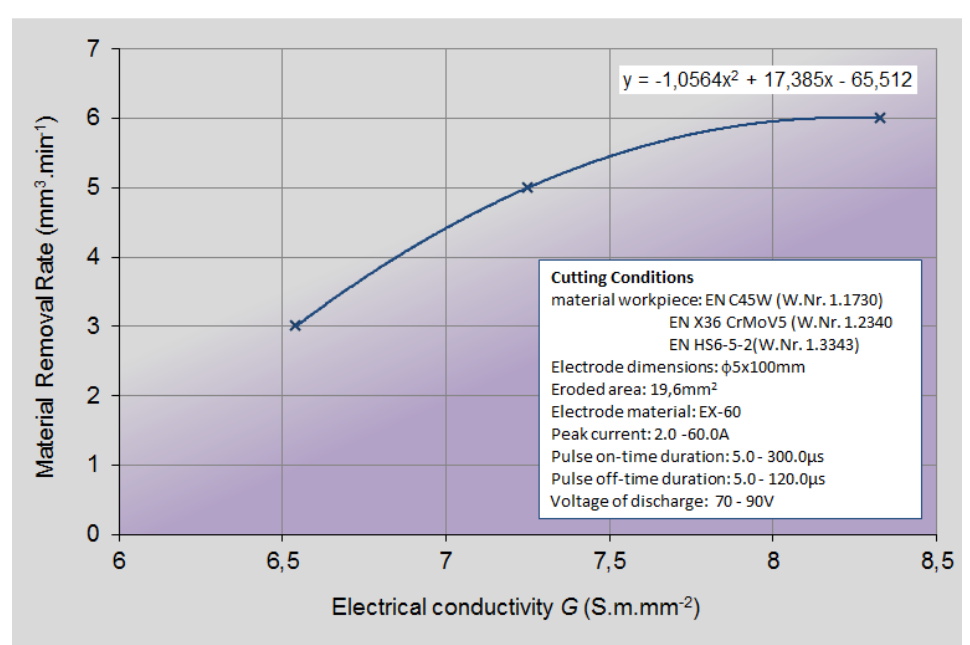

Figure 5. Dependence of MRR on the electrical conductivity G at EDM tool steels with graphite electrode EX-60. 
From the graphical dependence on Fig. 5 it can be seen that the magnitude of the MRR is increased with the increasing value of the electrical conductivity of the machined material in the range of $G=6.54$ to 8.33 S.m.mm ${ }^{-2}$ in EDM of tool steels with graphite electrode EX-60. Its value ranges from 3.0 to $6.0 \mathrm{~mm}^{3} \cdot \mathrm{min}^{-1}$. The lowest MRR $=3.0 \mathrm{~mm}^{3} \cdot \mathrm{min}^{-1}$ was achieved with the electrical conductivity of the machined material $G=6.54 \mathrm{~S} \cdot \mathrm{m} \cdot \mathrm{mm}^{-2}$. On the contrary, the highest value MRR $=6.0 \mathrm{~mm}^{3} \cdot \mathrm{min}^{-1}$ was achieved with the electrical conductivity of the machined material $G=8.33 \mathrm{~S} . \mathrm{m} . \mathrm{mm}^{-2}$. At the same time, from the graphical dependence, it can be assumed that at the value of the electrical conductivity of the workpiece under $G=6.0$ S.m.mm ${ }^{-2}$ the MRR will approach zero.

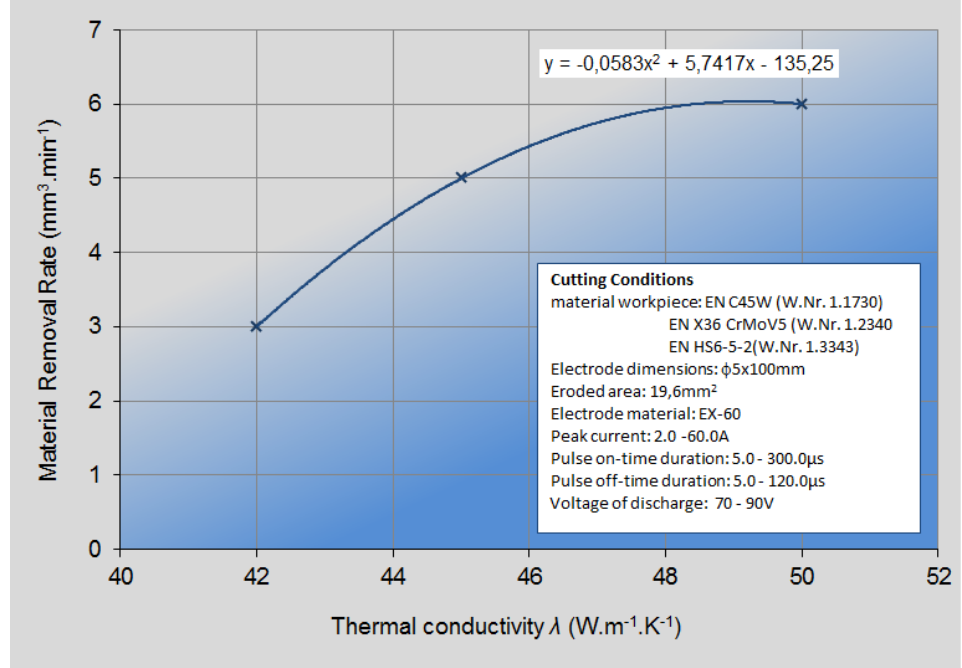

Figure 6. Dependence of MRR on thermal conductivity $\lambda$ at EDM of tool steels with graphite electrode EX-60.

From the graphical dependence on Fig. 6 it can be seen that the magnitude of the MRR increases with the increasing value of the thermal conductivity of the workpiece material in the range $\lambda=42$ to $50 \mathrm{~W} \cdot \mathrm{m}^{-1} \cdot \mathrm{K}^{-1}$ in EDM of tool steels with graphite electrode EX-60. Its value ranges from 3.0 to $6.0 \mathrm{~mm}^{3} \cdot \mathrm{min}^{-1}$. The lowest MRR $=3.0 \mathrm{~mm}^{3} \cdot \mathrm{min}^{-1}$ was achieved at the thermal conductivity of the workpiece material $\lambda=42 \mathrm{~W} \cdot \mathrm{m}^{-1} \cdot \mathrm{K}^{-1}$. On the contrary, the highest value MRR $=6.0 \mathrm{~mm}^{3} \cdot \mathrm{min}^{-1}$ was achieved at the thermal conductivity of the workpiece material $\lambda=50 \mathrm{~W} \cdot \mathrm{m}^{-1} \cdot \mathrm{K}^{-1}$. At the same time, from the graphical dependence, it can be assumed that at the value of the thermal conductivity of the workpiece under $\lambda=40 \mathrm{~W} \cdot \mathrm{m}^{-1} \cdot \mathrm{K}^{-1}$ the MRR will approach zero. Based on experimental research, it has been found that materials with higher thermal and electrical conductivity values have to be used to achieve the greatest possible material removal rate for EDM of tool steels.

\section{Conclusion}

For volume removal of material from the workpiece during the EDM is effected by a series of electrical discharges [14]. The volume stock removal from the workpiece may be characterized by a complex parameter MRR. From the point of view of productivity and economic efficiency of the electroerosion process it is advisable that the value of the given parameter be as high as possible $[15,16]$. As already described in the paper, its real value during EDM is directly dependent on the electrical and thermal conductivity of the machined material. The use of workpiece materials with a too low value for these 
two parameters results in a reduction in MRR and, in extreme cases, even the elimination of discharges between the tool electrode and the workpiece. The aim of the experiments was to identify the influence of the electrical and thermal conductivity of the workpiece material on EDM of tool steels EN C45W, EN X36 CrMoV5 and EN HS6-5-2 with graphite tool electrode EX-60. Based on the results of the experimental measurements, it was found that the increasing value of the electrical and thermal conductivity increases the value of the MRR parameter. Conversely, low electrical and thermal conductivity values result in a decrease in MRR, it may be assumed that even if the limit values of these parameters are reached, even the stability of the electro-erosion process can be lost, or even stopped.

\section{Acknowledgments}

The research work is supported by the VEGA Grants No. 1/0381/15 and by the KEGA Grant No. 004 TUKE-4/2017.

\section{References}

[1] F.L. Amorim - W.L. Weingaertner (2007) The behavior of graphite and copper electrodes on the finish die-Sinking electrical discharge machining (EDM) of AISI P20 tool Steel. J. Braz. Soc. Mech. Sci. Eng. 29. pp. 366-371.

[2] S. Hašová - L. Straka (2006) Design and verification of software for simulation of selected quality indicators of machined surface after WEDM. Academic Journal of Manufacturing Engineering. 14 (2) pp. 13-2, ISSN 1583-7904.

[3] C.H. Che Haron (2001) Investigation on the influence of machining parameters when machining tool steel using EDM. J. Mater. Process. Technol. 1. pp. 84-87.

[4] M. Kiyak - O. Cakir (2007) Examination of machining parameters on surface roughness in EDM of tool steel. J. Mater. Process. Technol. 1-3. pp. 41-144.

[5] S. Mathew - P.R.D. Varma - P.S. Kurian (2014) Study on the Influence of process parameters on surface roughness and MRR of AISI 420 stainless steel machined by EDM. Int. J. Eng. Trends Technol. 2. pp. 54-58.

[6] J. Marafona - C. Wykes (2000) A new method of optimizing material removal rate using EDM with copper-tungsten electrodes. Int. J. Mach. Tools Manuf. 40. pp. 153-164.

[7] A. Panda - M. Prislupčák - I. Pandová (2014) Progressive technology diagnostic and factors affecting to machinability. Applied Mechanics and Materials. 616 pp. 183-190. ISSN 1660-9336.

[8] S.K. Saha - S.K. Chaudhary (2009) Experimental investigation and empirical modeling of the dry electrical discharge machining process. Int. J. Mach. Tool. Manuf. 49. pp. 297-308.

[9] J.S, Soni - G. Chakraverti (1995) Effect of electrode material properties on surface roughness and dimensional accuracy in electro-discharge machining of high carbon high chromium die steel. J. Ind. Eng. 76. pp. 46-51.

[10] S. Singh - S. Maheshwari - P.C. Pandey (2004) Some investigations into the electric discharge machining of hardened tool steel using different electrode materials. J. Mater. Process. Technol. 149. pp. 272-277.

[11] L. Straka (2014) Analysis of Wire-Cut Electrical Discharge Machined Surface. LAP Lambert Academic Publishing, Germany. 98 p., ISBN 978-3-659-64435-1. 
International Journal of Engineering and Management Sciences (IJEMS) Vol. 4. (2019). No. 1

DOI: 10.21791/IJEMS.2019.1.29.

[12] L'. Straka - S. Hašová (2016) Assessing the influence of technological parameters on the surface quality of steel MS1 after WEDM, MM Science Journal. 11. pp. 1194-1200, ISSN 1803-1269.

[13] A.T. Salcedo - P.I. Arbizu - C.J.L. Perez (2017) Analytical modelling of energy density and optimization of the EDM machining parameters of inconel 600. Metals. 7 (5) pp.166.

[14] L. Straka - I. Čorný - J. Pitel' (2016) Properties evaluation of thin microhardened surface layer of tool steel after wire EDM. Metals. 6 (5) pp. 1-16, ISSN 2075-4701.

[15] L. Straka - I. Čorný - J. Pitel' - S. Hašová (2017) Statistical Approach to Optimize the Process Parameters of HAZ of Tool Steel EN X32CrMoV12-28 after Die-Sinking EDM with SF-Cu Electrode, Metals. 7 (2) pp. 1-22, ISSN 2075-4701.

[16] S.K. Tamang - N. Natarajan - M. Chandrasekaran (2017) Optimization of EDM process in machining micro holes for improvement of hole quality. J Braz. Soc. Mech. Sci. Eng. 39. pp. 12771287. 